\title{
Eukaryotic Plasmids with Toxoplasma gondii Dense Granule Antigen (GRA 5) and Microneme 3 (MIC3) Genes as a Cocktail DNA Vaccine and Evaluation of Immune Responses in BALB/C Mice
}

Ghaffarifar $\mathrm{F}^{1 *}$, Naserifar $\mathbf{R}^{2}$ and Jafari Madrak $\mathbf{M}^{3}$

${ }^{1}$ Parasitology and Entomology Department, Faculty of Medical Sciences, TarbiatModares University, Tehran, I. R. Iran

${ }^{2}$ Department of Medical Parasitology, Faculty of Medicine, Ilam University of Medical Sciences, Ilam, I. R. Iran

${ }^{3}$ Department of Medical Parasitology, Faculty of Medicine, Zahedan University of Medical Sciences, Zahedan, I. R. Iran

\begin{abstract}
Toxoplasma gondii is an obligate intracellular protozoan that causes toxoplasmosis in human and animal. This parasite is worldwide spread and about one third of people are seropositive. Toxoplasmosis in immuno compromised patients causes serious symptoms. Toxoplasma gondii has a lot of various immunogenic antigens. Excreted/secreted antigens could stimulate of the cell mediated immune response and hence it appears to be a good candidate for vaccine in toxoplasmosis. In this study Microneme3 (MIC3) and GRA5 of Toxoplasma gondii are used as DNA vaccine.

The results indicated that survival rate of mice that immunized by recombinant plasmid have significant differences with control groups. IgG and $\lg _{2 a}$ assay approved significant different between case and control groups $(\mathrm{P}<0.05)$. Cytokine assay indicated high level of IFN-Y and low level of IL4 for immunized groups. These results indicated DNA vaccine encoded MIC3 and GRA5 genes of Toxoplasma gondii capable to induced partially protection against toxoplasmosis.
\end{abstract}

Keywords: Toxoplasma gondii; DNA vaccine; MIC3; GRA5

\section{Introduction}

In toxoplasmosis excretory - secretory antigens and surface antigens have important role in stimulating protective immunity. For this reason antigen excretion - secretion are suggested as candidates for immunization studies [1]. Microneme antigens bind and invade host cells before rhoptry antigens and have a major role in the pathogenicity [2]. One of the most important antigens of Microneme is Microneme protein 3 (MIC3), which is an important protein intakes during the invasion of the host cell, secreted by Toxoplasma. These antigens can be expressed in the tachyzoites, bradyzoites and sporozoites forms.MIC3 is synthesized as a $40 \mathrm{kDa}$ protein and polymerized as double-stranded form with $90 \mathrm{kDa}$ molecular weight protein [3]. GRA antigens are candidates for vaccine and GRA5 have been found in the tachyzoites, bradyzoites and sporozoites forms too [4-11]. GRA5 is secreted as a soluble antigen into the parasitophorous vacuole and may be related to a critical function in parasite-host interactions [12].

The aim of this study was to determine whether DNA vaccination with dense granule protein GRA5 and microneme MIC3 could prime the immune system of $\mathrm{BALB} / \mathrm{c}$ mice as well as to examine the immunogenicity and protective efficacy of this DNA vaccine against lethal challenge infection with the highly virulent RH strain of $T$. gondii.

\section{Materials and Methods}

\section{Parasite}

The tachyzoites of Toxoplasma gondii $\mathrm{RH}$ strain that injected intraperitoneally by serial passage in BALB /c mice then collected and used for mice challenge. For antigen preparation the tachyzoites of Toxoplasma gondii RH strain washed with PBS and were stored in $-20^{\circ} \mathrm{C}$ freezer.

\section{Recombinant plasmid construction}

The DNA sequence of the Microneme 3 gene obtained from data bank website NCBI with accession No. AJ132530. All genes encoding the MIC3 about 2247bp and we selected $1052 \mathrm{bp}$ from the entire gene that located within 724 to 1775 and primers were designed with Gene Runner Software as follows [13].

Forward: 5' - CA CAAGCTTATGGCGCTCACCTTCATGGGGG $-3$

Reverse: 5' - ACAGATATCTCACGTCACGGTGTGGGCATGGT $-3$

GRA5: The sequence of GRA5 gene of T. gondii RH strain (complete code: $363 \mathrm{bp}$ ) was obtained from Gen Bank, with the accession No. EU918733. The size of PCR product was $363 \mathrm{bp}$, primers were designed with Gene Runner Software as follows [14].

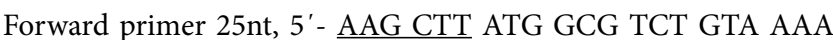
CGC G - 3

Hind III

Reverse primer $27 n t, 5^{\prime}$ - GAA TTC TTA CTC TTC CTC GGC AAC TTC - 3

EcoR I

*Corresponding author:Fatemeh Ghaffarifar, Parasitology and Entomology Department, Faculty of Medical Sciences, TarbiatModares University, Tehran, I.R Iran, P.O. Box 14115-331, Tel: +982182884553; Fax: +982182884555; E-mail: ghafarif@modares.ac.ir

Received Mar 30, 2015; Accepted Apr 11, 2015; Published Apr 18, 2015

Citation: Ghaffarifar F, Naserifar R, Jafari Madrak M (2014) Eukaryotic Plasmids with Toxoplasma gondii Dense Granule Antigen (GRA 5) and Microneme 3 (MIC3) Genes as a Cocktail DNA Vaccine and Evaluation of Immune Responses in BALB/C Mice. J Clin Med Genom 3: 121. doi: 10.4172/2472-128X.1000121

Copyright: (c) 2015 Ghaffarifar F, et al. This is an open-access article distributed under the terms of the Creative Commons Attribution License, which permits unrestricted use, distribution, and reproduction in any medium, provided the original author and source are credited. 
Citation: Ghaffarifar F, Naserifar R, Jafari Madrak M (2014) Eukaryotic Plasmids with Toxoplasma gondii Dense Granule Antigen (GRA 5) and Microneme 3 (MIC3) Genes as a Cocktail DNA Vaccine and Evaluation of Immune Responses in BALB/C Mice. J Clin Med Genom 3: 121. doi: $10.4172 / 2472-128 X .1000121$

Page 2 of 5

The recombinant plasmids were transformed into E. coli, strain TG1, and following mass replication of the bacterium were extracted from the bacteria using a plasmid extraction kit (Qiagen, Germany).

\section{Grouping of mice}

Mice were grouped according to the type of material that the name and number of each group is shown in the following table (Table 1).

\section{Immunization}

The mice used in this study were 6 to 8 week-old female BALB/c mice thatpurchased from Iran's Razi Serum and Vaccine Production Research Institute. Immunization in 3 times within 3 weeks interval (days zero, 21 and 42) and injection of $100 \mu \mathrm{l}$ per injection intramuscularly in the quadriceps of mice. For injection we used insulin syringe with needle gauge 30 in volume of $100 \mu \mathrm{l}$ for each injection (containing $100 \mu \mathrm{g}$ of the plasmid) (Table 1).

Four weeks after the last immunization and control groups, mice inoculated with $10^{4}$ of live tachyzoites of strain $\mathrm{RH}$ were challenged intraperitoneally. The survival rate of different groups of mice was recorded daily.

\section{Evaluation of IgG and subclasses}

Evaluation of humoral immunity in mice by measuring the serum levels of total IgG, IgG1 and IgG2a against Toxoplasma gondii in two blood samples using ELISA experiment was performed.

To determine the subclasses of antibodies Monoclonal Antibody Isotyping Reagents kit from Sigma Co. was used. The method that used was ELISA and performed according to the instructions Co. For ELISA Toxoplasma gondii lysate antigen (TLA) was used with $10 \mu \mathrm{g} / \mathrm{ml}$ concentration.

\section{Antigen preparation}

For Toxoplasma gondii lysate antigen (TLA) preparation, the tachyzoites were obtained from peritoneal infected mice. Phenyl-methane-sulfonyl-fluoride (PMSF) as anti- protease with concentration $1 \mathrm{mM}$ was added to tachyzoites and then Freeze \& Thaw and sonication were done.

\section{Cellular immunity}

Mouse spleen lymphocyte cultured for measuring the MTT and cytokines assay.

The presence of cytokines IL- 4 and IFN- $\gamma$ in cell culture of mouse spleen lymphocytes were evaluated in five groups of BALB/c mice (immunized and control groups). For this purpose, spleen cells were cultured according to the procedure below.

$500 \mathrm{ml}$ lymphocyte suspension from each mouse in two wells of 24-

\begin{tabular}{|c|c|c|c|}
\hline $\begin{array}{c}\text { Amount of injected } \\
\text { plasmid } \boldsymbol{\mu g} / \mathbf{1 0 0} \boldsymbol{\mu l}\end{array}$ & $\begin{array}{c}\text { No of mice for } \\
\text { immunological } \\
\text { assay }\end{array}$ & $\begin{array}{c}\text { No of mice } \\
\text { for survival } \\
\text { assay }\end{array}$ & Groups \\
\hline $50+50$ & 5 & 5 & pcMIC3 + pcDNA3 \\
\hline $50+50$ & 5 & 5 & pcGRA5+ pcDNA3 \\
\hline $50+50$ & 5 & 5 & pcMIC3+pcGRA5 \\
\hline 100 & 5 & 5 & pcDNA3 \\
\hline $100 \mu \mathrm{l}$ & 5 & 5 & PBS \\
\hline
\end{tabular}

Table 1: Grouping of mice and amount of injected plasmid according to different inserted plasmids

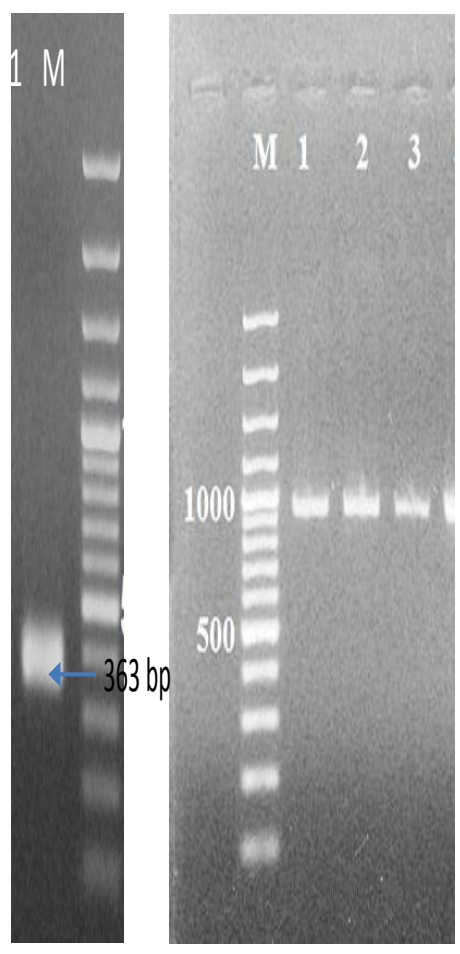

Figure 1: GRA5 and MIC3 PCR amplification and gel electrophoresis.

well culture plate was cultured and stimulated with $50 \mu \mathrm{g} / \mathrm{ml}$ of TLA. Plates were incubated for 72 hours in $37^{\circ} \mathrm{C}$ incubator with $5 \% \mathrm{CO}_{2}$ After this period, supernatants were collected and kept in $-70^{\circ} \mathrm{C}$ freezer.

\section{Cytokine assay}

The presence of cytokines IL- 4 and IFN- $\gamma$ in the supernatant of cells from mouse spleen lymphocytes was measured with kit (UcyTech Netherlands) according to manufacturer's recommendations.

\section{Statistical evaluation of the results}

To statistical analysis, the results of measurements of total IgG, IgG2a, IgG1, IFN- $\gamma$ and IL 4 and tested to investigate the survival of mice in different groups were entered in SPSS software information page.

As well as the survival of the rats tested in SPSS software information page compiled and compared with each other. Parametric test Kruskalwallis, Kaplan Meiere and Mann-whitney. To draw graphs and Excel software were used.

\section{Result}

Results of PCR amplification using plasmid DNA extracted from parasites using primers shown in Figure 1. This figure shows that 363 bp DNA fragment amplified by PCR was about the same size of GRA5 gene of Toxoplasma gondii. The primers designed to amplify is specific for GRA5 gene.

The results obtained by use of PCR on plasmid gene-specific primers MIC3 2 shows the DNA fragment amplified by PCR was about $1052 \mathrm{bp}$ and MIC3 Toxoplasma genes are of similar size and any genes other than gene amplification has not MIC3, so MIC3 gene -specific primers designed for amplification of Toxoplasma MIC3 gene specific primers PCR products in 1\% agarose gel ; line 1:PCR Product ( $1052 \mathrm{bp}$ gene fragment MIC3), M: marker $100 \mathrm{bp}$. 
Citation: Ghaffarifar F, Naserifar R, Jafari Madrak M (2014) Eukaryotic Plasmids with Toxoplasma gondii Dense Granule Antigen (GRA 5) and Microneme 3 (MIC3) Genes as a Cocktail DNA Vaccine and Evaluation of Immune Responses in BALB/C Mice. J Clin Med Genom 3: 121. doi: $10.4172 / 2472-128 X .1000121$

Page 3 of 5

MIC3 sequencing analysis of Toxoplasma gondii cloned in pTZ57R / T using the website www.ncbi.nlm.nih.gov / blast revealed that 1052 bp fragment was cloned in the plasmid is MIC3 gene of Toxoplasma gondii (Figure 1).

Lanes M 100bp DNA ladder.Lane 1, PCR product of GRA5 (363 bp) and MIC3 (1052 bp).

\section{Survival assay}

The results of survival assay in BALB/c mice after challenged with $10^{4}$ of tachyzoites of Toxoplasma gondii $\mathrm{RH}$ strain are shown in Fig. 2. The mean days of survival is 4, 4.6, 7.8, 7,8 and 8.6 for PBS, pc GNA3, GRA4, MIC3 and GRA4+MIC3 respectively (Figure 2).

\section{Results of humoral immunity}

Results of total IgG measurement: The lowest mean OD value for total IgG in the both of samplings related to the pc-DNA3 and PBS groups, and the highest values were obtained in pcGRA5 group. Furthermore, the cut-off value determined according to measurement of total IgG in serum samples of seronegative mice was (Meam $+3 \times$ SD) 0.234 (Table 2)

Results of the measurement of IgG1 isotype: With regard to the results provided in (Table 3 ), in the first and second blood samplings, the lowest mean OD values related to PBS group. The highest values related to pcGRA5+ pcMIC3 and pcMIC3 groups, respectively. However, the differences were not statistically significant $(p>0.05)$. Moreover, the cut-off value determined according the IgG1 measurement in serum sample of seronegative mice was $0.165+3 \times 0.006=0.183$ (Table 3 ).

Results of the measurement of IgG2a isotype :According to Table 3 , the lowest mean OD values in the first and second blood samplings

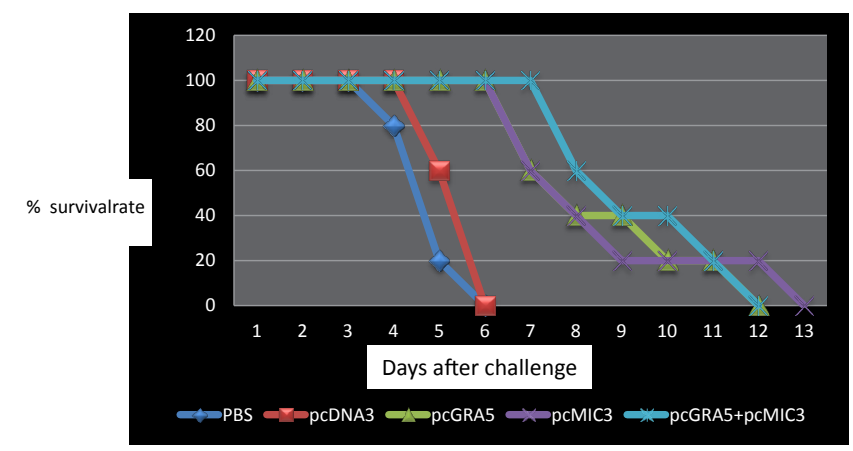

Figure 2: Survival rates of immunized and control BALB/c mice after lethal challenge with $1 \times 104$ tachyzoite forms of $\mathrm{T}$. gondii $\mathrm{RH}$ strain 4 weeks after the last immunization. Each group has five mice.

\begin{tabular}{|c|c|c|c|}
\hline \multirow{2}{*}{$\begin{array}{c}\text { Number of } \\
\text { group }\end{array}$} & Immunization regimen & \multicolumn{2}{|c|}{ Total IgG on day 42 } \\
\cline { 3 - 4 } & pcGRA5 & $0.024 \pm 0.27$ & $\begin{array}{c}\text { sig(P<0.05) } \\
\text { with groups }\end{array}$ \\
\hline 1 & SD \pm Mean & ${ }^{*}(4,5)$ \\
\hline 2 & pcMIC3+pcGRA5 & $0.018 \pm 0.29$ & ${ }^{*}(4,5)$ \\
\hline 3 & pcMIC3 & $0.025 \pm 0.255$ & ${ }^{*}(1,2,3)$ \\
\hline 4 & PBS & $0.027 \pm 0.153$ & ${ }^{*}(1,2,3)$ \\
\hline 5 & pcDNA3 & $0.016 \pm 0.167$ & \\
\hline
\end{tabular}

Significantly different from the groups considered in the parentheses according to ANOVA and Mann-whitneytests $(p<0.05)$.

Table 2: Comparison of mean OD values for total IgG determined using ELISA test in serum samples of mice for two blood samplings.

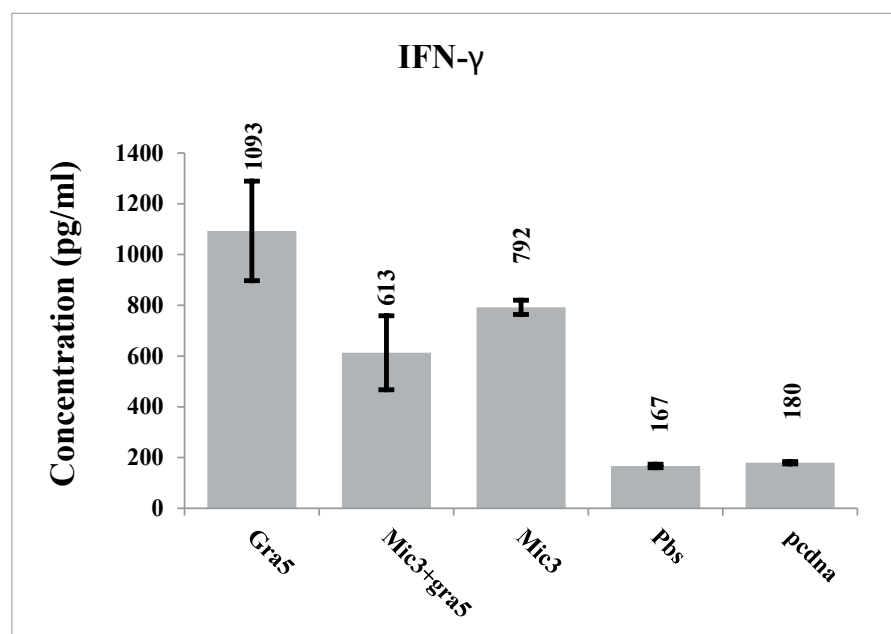

Figure 3: Comparison of mean \pm SD IFN- $-\gamma$ levels determined by ELISA in samples of mice studied 72 hours after lymphocyte culture with TLA.

\begin{tabular}{|c|c|c|c|}
\hline \multirow{2}{*}{ Number of group } & \multirow{2}{|c|}{$\begin{array}{c}\text { Immunization } \\
\text { regimen }\end{array}$} & \multicolumn{2}{|c|}{ IgG1 on day 42 } \\
\cline { 2 - 4 } & SD \pm Mean & $\begin{array}{c}\text { sig(P<0.05) } \\
\text { with groups }\end{array}$ \\
\hline 1 & pcGRA5 & $0.009 \pm 0.192$ & ${ }^{*}(2,3)$ \\
\hline 2 & pcMIC3+pcGRA5 & $0.187 \pm 0.311$ & ${ }^{*}(1,4,5)$ \\
\hline 3 & pcMIC3 & $0.104 \pm 0.282$ & $*(1,4,5)$ \\
\hline 4 & PBS & $0.006 \pm 0.165$ & ${ }^{*}(2,3)$ \\
\hline 5 & pcDNA3 & $0.024 \pm 0.178$ & ${ }^{*}(2,3)$ \\
\hline
\end{tabular}

Significantly different from the groups considered in the parentheses according to ANOVA and Mann-whitneytests $(p<0.05)$.

Table 3: Comparison of mean OD values of IgG1 determined by ELISA in the mice in two blood samplings.

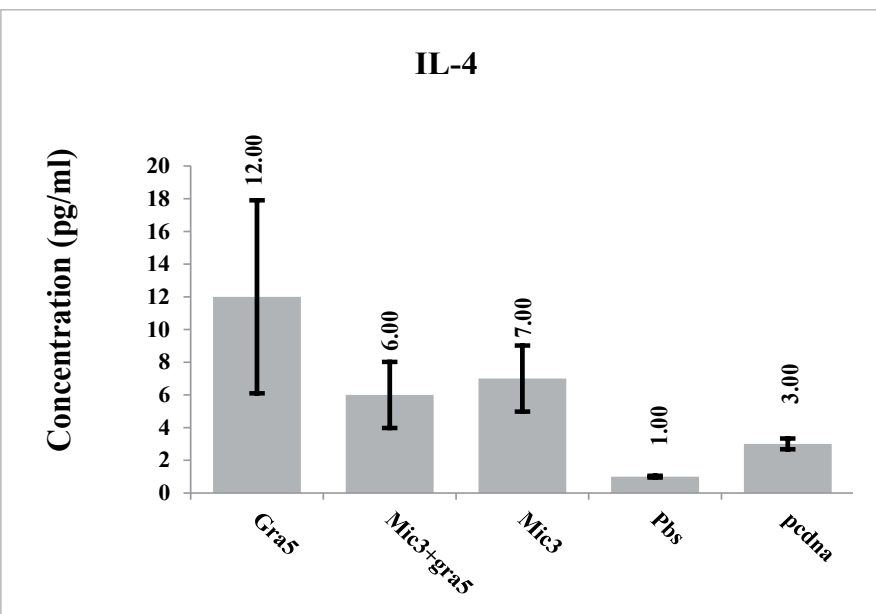

Figure 4: Comparison of mean \pm SD IL-4 levels determined by ELISA in samples of mice studied 72 hours after lymphocyte culture with TLA.

were obtained for the pcDNA3 and PBS groups, respectively. This is while the highest values related topcMIC3 and pcGRA5+ pcMIC3 groups respectively. Furthermore, the cut-off value obtained according to IgG2a measurement in serum sample of seronegative mice was $0.149+3 \times 0.005=0.164$ (Table 4$)$.

\section{Results of cellular immunity}

Results of IFN- $\gamma$ and IL-4 measurement: As shown in (Figure $3,4)$ the mice immunized with pcGRA5 elicited stronger IFN- $\gamma$ and 
Citation: Ghaffarifar F, Naserifar R, Jafari Madrak M (2014) Eukaryotic Plasmids with Toxoplasma gondii Dense Granule Antigen (GRA 5) and Microneme 3 (MIC3) Genes as a Cocktail DNA Vaccine and Evaluation of Immune Responses in BALB/C Mice. J Clin Med Genom 3: 121. doi: $10.4172 / 2472-128 X .1000121$

Page 4 of 5

\begin{tabular}{|c|c|c|c|}
\hline \multirow{2}{*}{$\begin{array}{c}\text { Number } \\
\text { of group }\end{array}$} & \multirow{2}{*}{$\begin{array}{c}\text { Immunization } \\
\text { regimen }\end{array}$} & \multicolumn{2}{|c|}{ IgG2a on day $\mathbf{4 2}$} \\
\cline { 3 - 4 } & SD \pm Mean & $\begin{array}{c}\text { sig(P<0.05) } \\
\text { with groups }\end{array}$ \\
\hline 1 & pcGRA5 & $0.050 \pm 0.225$ & $*(4,5)$ \\
\hline 2 & pcMIC3 +pcGRA5 & $0.051 \pm 0.247$ & ${ }^{*}(4,5)$ \\
\hline 3 & pcMIC3 & $0.028 \pm 0.257$ & ${ }^{*}(4,5)$ \\
\hline 4 & PBS & $0.005 \pm 0.149$ & $*(1,2,3)$ \\
\hline 5 & pcDNA3 & $0.004 \pm 0.144$ & $*(1,2,3)$ \\
\hline
\end{tabular}

Significantly different from the groups considered in the parentheses according to ANOVA and Mann-whitneytests $(p<0.05)$

Table 4: Comparison of mean OD values for IgG2a determined using ELISA test in serum samples of mice for two blood samplings.

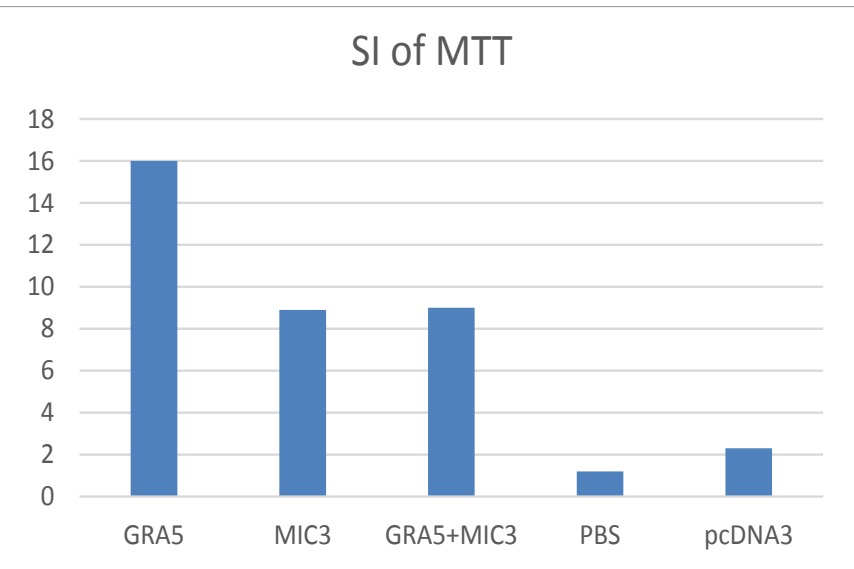

Figure 5: SI value obtained according to MTT assay, after the lymphocyte culture stimulated with Toxoplasma gondi antigen in the experiment and control groups.

IL-4 responses than other groups. Significant high level of IFN- $\gamma$ was observed in spleen cell cultures in mice immunized with pcGRA5 compared with control groups $(\mathrm{P}<0.05)$.

Results of MTT assay: The stimulation index (SI) calculated according MTT assay for all groups after the stimulation of lymphocytes with antigen is shown in fig. The results showed the most SI is for GRA5 group that were obtained 16 (Figure 5).

\section{Discussion}

Toxoplasmosis is one of the most common infections of humans during its importance in immuno compromised patients is congenital. Since the mother is the time period of pregnancy complications is different. Thus, clearly indicate the need for the development of a more effective vaccine [15]. Research has shown that DNA vaccines could protect humans and animals against intracellular parasites. In recent years, extensive research in finding the right candidates that can induce a protective immune response that has been done. The previous study showed that excretory secretory antigens of $T$. gondii have a main role in stimulating the protective immune system [16]. MIC3 andGRA5 have been found in all stages of the parasite. These results indicated DNA vaccine encoded GRA5 andMIC3 genes of Toxoplasma gondii capable to induced partial protection against Toxoplasmosis.

MIC3 is an efficient and strong antigen of T. gondii that have been secreted in all stages of the parasite and for this reason is suitable candidate for vaccine [2]. The results show that recombinant plasmids contain GRA5 and MIC3 genes separately and in combination with each other capable to stimulate the immune system and increase the survival rate. Recombinant plasmid inserted with MIC3 gene of $T$. gondii capable to stimulate cellular immunity with production of high level of IFN- $\gamma$ and low level of IL-4. MIC3.

The protein of MIC3 has a main role in recognize and attachment to host cells. This protein secreted from microneme in progress of host cell by parasites. MIC3 is very immunogenic antigen in rapid diagnosis latex agglutination test [17]. Ismael et al. found that vaccination of $\mathrm{CBA} / \mathrm{J}$ mice with inserted plasmid with MIC3 gene could produce high level of IgG against MIC3 and the immune response increased with injection of cloned plasmid with PGM-CSF gene [18].

This study was supported by funds from Iran National Science Foundation.

\section{Acknowledgments}

This study was supported by funds from Iran National Science Foundation.

\section{Conflict of interest}

The authors have no conflicts of interest to declare.

\section{References}

1. Cesbron-Delauw MF (1994) Dense-granule organelles of Toxoplasma gondii: their role in the host-parasite relationship. Parasitol Today 10: 293-296.

2. Soldati D, Dubremetz JF, Lebrun M (2001) Microneme proteins: structura and functional requirements to promote adhesion and invasion by the apicomplexan parasite Toxoplasma gondii. Int J Parasitol 31: 1293-1302.

3. Striepen B, Soldati D, Garcia-Reguet N, Dubremetz JF, Roos DS (2001) Targeting of soluble proteins to the rhoptries and micronemes in Toxoplasma gondii. Mol Biochem Parasitol 113: 45-53.

4. Bivas-Benita M, Laloup M, Versteyhe S, Dewit J, De Braekeleer J, et al (2003) Generation of Toxoplasma gondii GRA1 protein and DNA vaccine loaded chitosan particles: preparation, characterization, and preliminary in vivo studies. Int J Pharm 266: 17-27.

5. Golkar M, Shokrgozar MA, Rafati S, Musset K, Assmar M, et al. (2007) Evaluation of protective effect of recombinant dense granule antigens GRA2 and GRA6 formulated in monophosphoryl lipid A (MPL) adjuvant against Toxoplasma chronic infection in mice. Vaccine 25: 4301-4311.

6. Jongert E, De Craeye S, Dewit J, Huygen K (2007) GRA7 provides protective immunity in cocktail DNA vaccines against Toxoplasma gondii. Parasite Immunol 29: 445-453.

7. Martin V, Supanitsky A, Echeverria PC, Litwin S, Tanos T, et al. (2004) Recombinant GRA4 or ROP2 protein combined with alum or the gra4 gene provides partial protection in chronic murine models of toxoplasmosis. Clin Diagn Lab Immunol 11: 704-710.

8. Mevelec MN, Bout D, Desolme B, Marchand H, Magne R, et al. (2005) Evaluation of protective effect of DNA vaccination with genes encoding antigens GRA4 and SAG1 associated with GM-CSF plasmid, against acute, chronical and congenital toxoplasmosis in mice. Vaccine 23: 4489-4499.

9. Scorza T, D'Souza S, Laloup M, Dewit J, De Braekeleer J, et al. (2003) A GRA1 DNA vaccine primes cytolytic CD8(+) T cells to control acute Toxoplasma gondii infection. Infect Immun 71: 309-316.

10. Vercammen M, Scorza T, Huygen K, De Braekeleer J, Diet R, et al. (2000) DNA vaccination with genes encoding Toxoplasma gondii antigens GRA GRA7, and ROP2 induces partially protective immunity against letha challenge in mice. Infect Immun 68: 38-45.

11. Tilley M, Fichera ME, Jerome ME, Roos DS, White MW (1997) Toxoplasma gondii sporozoites form a transient parasitophorous vacuole that is impermeable and contains only a subset of dense-granule proteins. Infect Immun 65: 4598-4605.

12. Lecordier L, Mercier C, Sibley LD, Cesbron-Delauw MF (1999) Transmembrane insertion of the Toxoplasma gondii GRA5 protein occurs after soluble secretion into the host cell. Mol Biol Cell 10: 1277-1287.

13. Jafari-Modrek M, Ghaffarifar F, Sharifi Z, Dalimi-Asl A (2011) Cloning and sequencing the plasmid encoding Toxoplasma gondii Microneme 3 protein. Journal of Kashan University of Medical Sciences, Autumn 15: 200-206. 
Citation: Ghaffarifar F, Naserifar R, Jafari Madrak M (2014) Eukaryotic Plasmids with Toxoplasma gondii Dense Granule Antigen (GRA 5) and Microneme 3 (MIC3) Genes as a Cocktail DNA Vaccine and Evaluation of Immune Responses in BALB/C Mice. J Clin Med Genom 3: 121. doi: $10.4172 / 2472-128 X .1000121$

Page 5 of 5

14. Naserifar R, Ghaffarifar F, Dalimi-AsIA, Sharifi Z (2011) Cloning of Toxoplasma gondii granular antigen 5 (GRA5) in expression eukaryotic plasmid pcdna3 and its expression on cho cell. J Ilam Univ Med Sci19:1-12.

15. Zhang J, He S, Jiang H, Yang T, Cong H, et al. (2007) Evaluation of the immune response induced by multiantigenic DNA vaccine encoding SAG1 and ROP2 of Toxoplasma gondii and the adjuvant properties of murine interleukin-12 plasmid in BALB/c mice. Parasitol Res 101: 331-338.

16. Mercier C, Lecordier L, Darcy F, Deslee D, Murray A, et al. (1993) Molecular characterization of a dense granule antigen (Gra 2) associated with the network of the parasitophorous vacuole in Toxoplasma gondii. Mol Biochem Parasitol 58: 71-82.

17. Jiang T,Zhang D, NieH, YaoB, Zhao J (2008) Construction and expression of the eukaryotic expressed plasmid of MIC3 gene from Toxoplasma gondii in IBRS-2 cells. Front Agric Chin 2:498-501.

18. Ismael AB, Sekkai D, Collin C, Bout D, Mévélec MN (2003) The MIC3 gene of Toxoplasma gondii is a novel potent vaccine candidate against toxoplasmosis. Infect Immun 71: 6222-6228. 